\title{
Effect of glucosamine, a therapeutic agent for osteoarthritis, on osteoblastic cell differentiation
}

\author{
MAMORU IGARASHI ${ }^{1}$, KOJI SAKAMOTO ${ }^{2}$ and ISAO NAGAOKA ${ }^{1}$ \\ ${ }^{1}$ Department of Host Defense and Biochemical Research, Graduate School of Medicine, Juntendo University, Bunkyo-ku, \\ Tokyo 113-8421; ${ }^{2}$ Koyo Chemical Co., Ltd., 3-11-15 Iidabashi, Chiyoda-ku, Tokyo 102-0072, Japan
}

Received February 4, 2011; Accepted March 22, 2011

DOI: $10.3892 / \mathrm{ijmm} .2011 .686$

\begin{abstract}
Osteoarthritis (OA) is characterized by qualitative and quantitative changes in the architecture and composition of all the joint structures. Glucosamine (GlcN) has been used to treat $\mathrm{OA}$ in humans, because $\mathrm{GlcN}$ is present in the cartilage tissues as a component of glycosaminoglycans, and exhibits the symptom-modifying effect on OA by normalizing cartilage metabolism. On the other hand, the pathological change of subchondral bone is associated with the initiation and progression of cartilage damage in OA. However, the effect of GlcN on bone metabolism remains unsolved. In the present study, we determined the effect of GlcN on bone metabolism (osteoblastic cell differentiation) using mouse osteoblastic MC3T3-E1 cells by evaluating the expression of early (type I collagen and alkaline phosphatase), middle (osteopontin) and late (osteocalcin and mineralization) stage differentiation markers, and further compared its effects to those of N-acetyl-D-glucosamine (GlcNAc), a derivative of GlcN. The results indicated that the mineralization of mature osteoblasts was increased by treatment with GlcN and GlcNAc. Furthermore, reverse transcription-polymerase chain reaction (RT-PCR) analyses revealed that GlcN and GlcNAc substantially increased the expression of a middle stage marker and a late stage marker, although they did not essentially affect the expression of early stage markers. In addition, GlcN and GlcNAc suppressed the expression of receptor activator of NF- $\mathrm{KB}$ ligand (RANKL), a key factor involved in the osteoclastic cell differentiation and activation. Together these observations suggest that both GlcN and GlcNAc may have a potential not only to induce osteoblastic cell differentiation especially at middle-late stages, but also to suppress the osteoclastic cell differentiation, thereby possibly increasing
\end{abstract}

Correspondence to: Dr Isao Nagaoka, Department of Host Defense and Biochemical Research, Graduate School of Medicine, Juntendo University, 2-1-1 Hongo, Bunkyo-ku, Tokyo 113-8421, Japan E-mail: nagaokai@juntendo.ac.jp

Key words: glucosamine, osteoblast, osteocalcin, receptor activator of NF- $\mathrm{NB}$ ligand bone matrix deposition and decreasing bone resorption, and eventually modulating bone metabolism in OA.

\section{Introduction}

Osteoarthritis (OA) is the most common joint disorder with an immense socioeconomic impact. OA is characterized by qualitative and quantitative changes in the architecture and composition of all the joint structures $(1,2)$. An altered imbalance between the biosynthesis and the degradation of matrix components leads to a progressive destruction of the tissue (3). Currently, several treatments are available for OA ranging from conservative measures to more surgical extremes. Conservative measures involve lifestyle modifications, physical therapy and pharmacological treatment with nonsteroidal antiinflammatory drugs and intra-articular injection of hyaluronic acid (4). Treatments for early OA are primarily based on symptomatic relief, whereas irreversible joint disability in advanced OA usually requires surgical intervention to relieve pain and improve joint function (5). However, current treatments are mostly targeting the symptoms and not addressing the destructed structure of articular cartilage in OA.

D-Glucosamine $(\mathrm{GlcN})$, a naturally occurring amino monosaccharide, is present in the connective and cartilage tissues as a component of glycosaminoglycans, and contributes to maintaining the strength, flexibility and elasticity of these tissues. According to the biochemical and pharmacological findings, the administration of GlcN normalizes cartilage metabolism, so as to inhibit the degradation (6) and stimulate the synthesis of proteoglycans $(7,8)$, and to restore articular function. Thus, GlcN has been widely used to treat OA in humans for more than two decades (9-12). In this context, several short- and long-term clinical trials in OA have shown the significant symptom-modifying effect of GlcN (13-15). Moreover, the updated Osteoarthritis Research Society International (OARSI) recommendations for management of hip and knee OA have suggested that GlcN has symptomrelieving and structure-modifying effects in knee OA (16). In addition, we have previously demonstrated that GlcN is able to suppress cytokine-induced synovial cell activation (such as nitric oxide-, $\mathrm{PGE}_{2}$ - and IL-8-production), thereby possibly exhibiting anti-inflammatory actions in arthritis (17).

On the other hand, it is known that the pathological change of subchondral bone is associated with the initiation 
Table I. Gene specific PCR primers, annealing temperature $\left({ }^{\circ} \mathrm{C}\right)$ and number of PCR cycles.

\begin{tabular}{|c|c|c|c|c|}
\hline Genes & Forward primer & Reverse primer & Annealing temperature $\left({ }^{\circ} \mathrm{C}\right)$ & Number of cycles \\
\hline $\mathrm{COL}^{\mathrm{a}}$ & $5^{\prime}$-accatctggcatctcatggc-3' & 5'-gcaacacaattgcacctgagg-3' & 53 & 27 \\
\hline $\mathrm{ALP}^{\mathrm{b}}$ & $5^{\prime}$-gactggtactcggataacgagatgc-3' & 5'-tgcggttccagacatagtgg-3' & 55 & 31 \\
\hline $\mathrm{OPN}^{\mathrm{b}}$ & $5^{\prime}$-cattgcetcetccetcceggtg-3' & $5^{\prime}$-gctatcacctcggccgttgggg-3' & 62 & 28 \\
\hline $\mathrm{OCN}^{\mathrm{a}}$ & $5^{\prime}-\operatorname{tgcgctctgtctctctgacc-3'}$ & 5'-ctgtgacatccatacttgcagg-3' & 62 & 26 \\
\hline RANKL & $5^{\prime}-$ cctccegctccatgttcctgg-3' & 5'-cgtacaggtaatagaagccatcttgg-3' & 58 & 37 \\
\hline $\mathrm{GAPDH}^{\mathrm{c}}$ & 5'-accacagtccatgccatcac-3' & 5'-tccaccaccetgttgctgta-3' & 60 & 20 \\
\hline
\end{tabular}

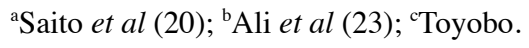

and progression of cartilage damage in OA (18). Due to non-physiological load-bearing to the subchondral bone, the bone resorption increases, thereby enhancing the progression of cartilage damage in OA (19). However, the effect of GlcN, a therapeutic agent for OA, on bone metabolism is not fully understood. To address this, in the present study, we examined the effect of GlcN on the bone metabolism using mouse osteoblastic MC3T3-E1 cells by examining osteoblastic cell differentiation, and compared it with that of N-acetyl-Dglucosamine (GlcNAc), a derivative of GlcN.

\section{Materials and methods}

Reagents. GlcN, GlcNAc, alizarin red-S (AR-S) and paraformaldehyde were purchased from Wako Pure Chemical Industries Ltd. (Osaka, Japan). Dexamethasone and ascorbic acid were purchased from Sigma-Aldrich (MO, USA). $\beta$-glycerophosphate was purchased from Calbiochem (CA, USA).

Cells. Mouse osteoblastic MC3T3-E1 cells, which were established from newborn mouse calvaria, were purchased from RIKEN Cell Bank (RCB 1126, Tsukuba, Japan). The MC3T3-E1 cells were maintained in $\alpha$-minimum essential medium (Gibco Invitrogen, Carlsbad, CA, USA) containing $10 \%$ heat-inactivated fetal bovine serum (FBS), penicillin and streptomycin at $37^{\circ} \mathrm{C}$ in $5 \% \mathrm{CO}_{2}$. To induce osteoblastic differentiation of MC3T3-E1 cells, the cells were fed with differentiation medium (DM: normal medium supplemented with $500 \mathrm{nM}$ dexamethasone, $10 \mathrm{mM} \beta$-glycerophosphate and $50 \mathrm{mg} / \mathrm{ml}$ ascorbic acid). The medium was changed every third day $(20,21)$.

AR-S staining. MC3T3-E1 cells $\left(1 \times 10^{8}\right.$ cells/well) were seeded in 6-well plates overnight. After changing the medium to DM, the cells were incubated in the absence or presence of GlcN ( 0.1 or $1 \mathrm{mM})$ or GlcNAc $(1 \mathrm{mM})$ for 21 days. The incubation media were changed every third day with further addition of GlcN or GlcNAc. After the incubation, the cells were washed twice with ice-cold phosphate-buffered saline (PBS; $137 \mathrm{mM}$ $\mathrm{NaCl}, 2.7 \mathrm{mM} \mathrm{KCl}, 8.1 \mathrm{mM} \mathrm{Na} \mathrm{HPO}_{4}, 1.5 \mathrm{mM} \mathrm{KH_{2 }} \mathrm{PO}_{4}$, $\mathrm{pH} 7.4$ ), and fixed with $2 \%$ paraformaldehyde for $15 \mathrm{~min}$ at $4^{\circ} \mathrm{C}$. The cells were then washed twice with ice-cold PBS and once with ice-cold distilled water. After the washing, the AR-S staining solution (40 mM AR-S, pH 4.2 adjusted by $1 \% \mathrm{KOH}$ solution) was added to each well ( $1 \mathrm{ml} /$ well $)$, followed by incubation for $15 \mathrm{~min}$ at room temperature with gentle rocking. The cells were then washed five times with distilled water, followed by rinsing with PBS for $15 \mathrm{~min}$ with gentle rocking to reduce non-specific AR-S staining. Stained cells were photographed, and then lysed in $10 \%$ hexadecylpyridinium chloride (Nacalai Tesque, Kyoto, Japan)-10 mM sodium phosphate-buffer ( $\mathrm{pH}$ 7.0) for $1 \mathrm{~h}$ at room temperature with gentle rocking. For quantification, the concentration of AR-S in each sample was determined by absorbance at $562 \mathrm{~nm}(20-22)$.

Semi-quantitative reverse transcription-polymerase chain reaction ( $R T-P C R)$. MC3T3-E1 cells $\left(2 \times 10^{8}\right.$ cells/dish) were seeded in $6 \mathrm{~cm}$ plates overnight. After changing the medium to $\mathrm{DM}$, the cells were incubated in the absence or presence of GlcN $(0.1$ or $1 \mathrm{mM})$ or GlcNAc $(1 \mathrm{mM})$ up to 21 days. The incubation media were changed every third day with further addition of GlcN or GlcNAc. After the incubation, the cells were collected by a cell scraper (Sumitomo Bakelite Co., Ltd., Tokyo, Japan). Then, total-RNA was purified using an RNeasy plus mini kit (Qiagen, CA, USA) and QIAshredder (Qiagen) to remove contaminated DNA, according to the manufacturer's protocol, and stored at $-80^{\circ} \mathrm{C}$. RT-PCR was performed using a ReverTra-Plus RT-PCR kit (Toyobo, Osaka, Japan), and PCR amplification was performed with the GoTaq Master mix (Promega, WI, USA) in a thermal cycler (GeneAmp PCR System 9700, Applied Biosystems, CA, USA) for type I collagen (COLI), alkaline phosphatase (ALP), osteopontin (OPN), osteocalcin (OCN), receptor activator of NF- $\mathrm{B}$ ligand (RANKL) and for glyceraldehyde-3-phosphate dehydrogenase (GAPDH), according to the manufacturer's protocol. In brief, cDNA was synthesized by reverse transcription of total RNA (500 ng) using ReverTra Ace reverse transcriptase and oligo(dt)20. To discriminate mRNA-derived PCR products from genomic DNA-derived products, the intron-spanning PCR primers were used with the annealing temperature and cycle number indicated in Table I. PCR products were resolved by $2 \%$ agarose gel electrophoresis in $1 \mathrm{X}$ Tris-acetate-EDTA buffer and stained with ethidium bromide. In our preliminary experiments, we tried to semi-quantitatively detect mRNA by using different numbers of PCR cycles. The results revealed that the amounts of RT-PCR products increased as the cycle number increased. Thus, we decided to measure the mRNA levels by RT-PCR with the number of cycles indicated in 

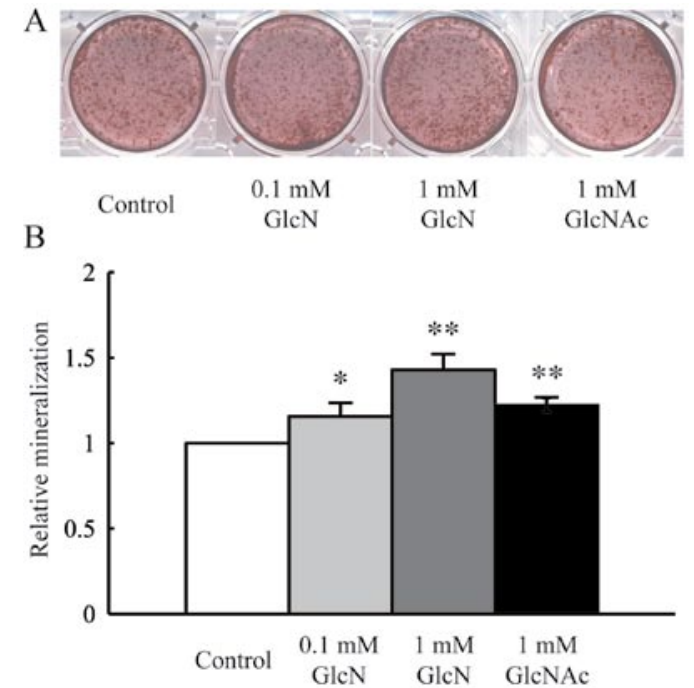

Figure 1. Effects of GlcN and GlcNAc on the mineralization of osteoblasts. Mouse osteoblastic cells (MC3T3-E1) were differentiated in differentiation medium in the absence (Control) or presence of GlcN $(0.1$ and $1 \mathrm{mM})$ or GlcNAc (1 mM) for 21 days. (A) AR-S staining. (B) Quantification of AR-S staining. Concentration of AR-S was expressed as a ratio relative to Control. Data represent the mean \pm SD of three independent experiments. Values were compared between the absence (Control) and presence of GlcN or GlcNAc. ${ }^{*} \mathrm{P}<0.05 ;{ }^{* *} \mathrm{P}<0.01$.

Table I. The detected bands were quantified using MultiGauge (Version 3.0, FujiFilm, Tokyo, Japan).

Statistical analysis. Data are expressed as the mean $\pm \mathrm{SD}$, and analyzed for significant differences by a Student's t-test using Excel. Differences were considered statistically significant at $\mathrm{P}<0.05$.

\section{Results}

Effects of GlcN and GlcNAc on the mineralization of osteoblastic MC3T3-E1 cells. Mineralization of differentiated osteoblastic MC3T3-E1 cells was measured after the incubation with GlcN or GlcNAc for 21 days. GlcN significantly increased the mineralization at $0.1(\mathrm{P}<0.05)$ and $1 \mathrm{mM}$ $(\mathrm{P}<0.01)$ compared with control without $\mathrm{GlcN}$ and GlcNAc (Fig. 1). Moreover, GlcNAc significantly increased the mineralization at $1 \mathrm{mM}(\mathrm{P}<0.01)$ (Fig. 1). Notably, GlcN was more potent than GlcNAc in inducing mineralization at the same concentration (Fig. 1).

Effects of GlcN and GlcNAc on the osteoblastic differentiation of MC3T3-E1 cells. Osteoblastic cells express differentiation markers, such as COLI and ALP which are markers for the early stage of osteoblastic differentiation, OPN, a marker for middle stage differentiation, and $\mathrm{OCN}$, a marker for late stage differentiation (24-29). Thus, the effect of GlcN on osteoblastic cell differentiation was investigated by measuring the expression of differentiation markers by RT-PCR. First, the expression of the markers for the early stage of osteoblastic differentiation (COLI and ALP) was evaluated. The expression of COLI was not changed by GlcN $(0.1$ and $1 \mathrm{mM})$ after incubation for 1-3 days, compared to the control without GlcN and GlcNAc (Fig. 2). In contrast, the expression of COLI was

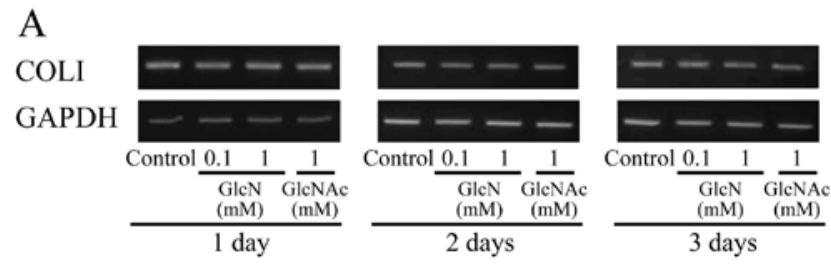

B



Figure 2. Effects of GlcN and GlcNAc on the mRNA expression of type I collagen (COLI). Osteoblastic cells (MC3T3-E1) were differentiated in differentiation medium in the absence (Control) or presence of GlcN ( 0.1 and $1 \mathrm{mM})$ or GlcNAc $(1 \mathrm{mM})$ for 3 days. After the incubation, total-RNA was purified, and the mRNA expression of COLI was evaluated by RT-PCR. (A) PCR products were resolved by $2 \%$ agarose gel electrophoresis, and stained with ethidium bromide. (B) COLI mRNA expression was expressed as a ratio relative to Control. Data represent the mean $\pm \mathrm{SD}$ of three independent experiments. Values were compared between the absence (Control) and presence of GlcN or GlcNAc. ${ }^{*} \mathrm{P}<0.05$.

slightly, but significantly, decreased by GlcNAc $(1 \mathrm{mM})$ after 2 days of incubation (Fig. 2). Furthermore, the expression of ALP was not substantially changed by either GlcN or GlcNAc (Fig. 3).

The expression of OPN, a marker for middle stage differentiation, was also evaluated. The expression of OPN was not changed by GlcN nor by GlcNAc after incubation for 7 days. However, the expression was apparently increased by both GlcN and GlcNAc (1 mM) after the incubation for 21 days (Fig. 4), although the change was not statistically significant. Furthermore, the expression of a marker for late stage of OCN was evaluated. Of importance, the expression of OCN was significantly $(\mathrm{P}<0.05)$ increased by GlcN $(1 \mathrm{mM})$ after the incubation for 21 days (Fig. 5). The expression of OCN was also increased by GlcNAc after 21 days, although the change was not significant.

Effects of GlcN and GlcNAc on the expression of RANKL by MC3T3-E1 cells. Bone tissue is continuously remodeled through the combined activities of two cell types, osteoblasts and osteoclasts. Osteoblasts deposit bone matrix, whereas osteoclasts resorb bone matrix. The bone deposition and resorption are tightly coupled, and their balance defines both the mass as well as the quality of the bone tissue (30-32). RANKL, which is expressed and secreted by mature osteoblasts, is a key factor of osteoclastogenesis $(33,34)$. Thus, the expression of RANKL was evaluated during osteoblastic differentiation of MC3T3-E1 cells by RT-PCR. Of note, the expression of RANKL was significantly $(\mathrm{P}<0.05)$ suppressed 
A
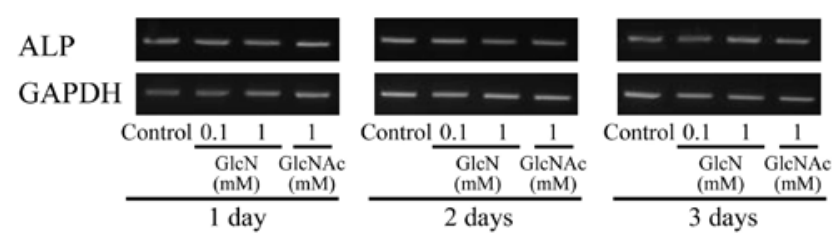

B

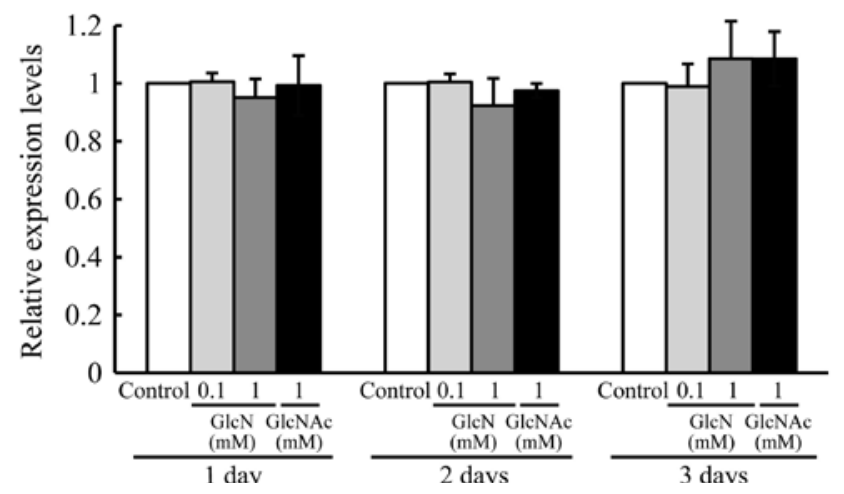

Figure 3. Effects of GlcN and GlcNAc on the mRNA expression of alkaline phosphatase (ALP). Osteoblastic cells (MC3T3-E1) were differentiated in differentiation medium in the absence (Control) or presence of GlcN ( 0.1 and $1 \mathrm{mM})$ or GlcNAc $(1 \mathrm{mM})$ for 3 days. After the incubation, total RNA was purified, and the expression of mRNA for ALP was evaluated by RT-PCR. (A) PCR products were resolved by $2 \%$ agarose gel electrophoresis, and stained with ethidium bromide. (B) ALP mRNA expression is expressed as a ratio relative to Control. Data represent the mean $\pm \mathrm{SD}$ of three independent experiments. Values were compared between the absence (Control) and presence of GlcN or GlcNAc.


Figure 4. Effects of GlcN and GlcNAc on the mRNA expression of osteopontin (OPN. Osteoblastic cells (MC3T3-E1) were differentiated in differentiation medium in the absence (Control) or presence of GlcN $(0.1$ and $1 \mathrm{mM})$ or GlcNAc $(1 \mathrm{mM})$ for 21 days. After the incubation, total-RNA was purified, and the OPN mRNA expression was evaluated by RT-PCR. (A) PCR products were resolved by $2 \%$ agarose gel electrophoresis, and stained with ethidium bromide. (B) OPN mRNA expression is expressed as a ratio relative to Control. Data represent the mean $\pm \mathrm{SD}$ of three independent experiments. Values were compared between the absence (Control) and presence of GlcN or GlcNAc.

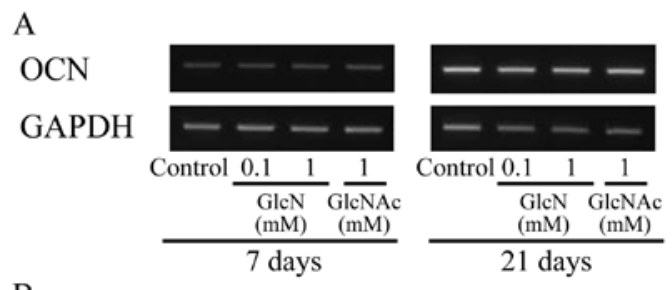

B

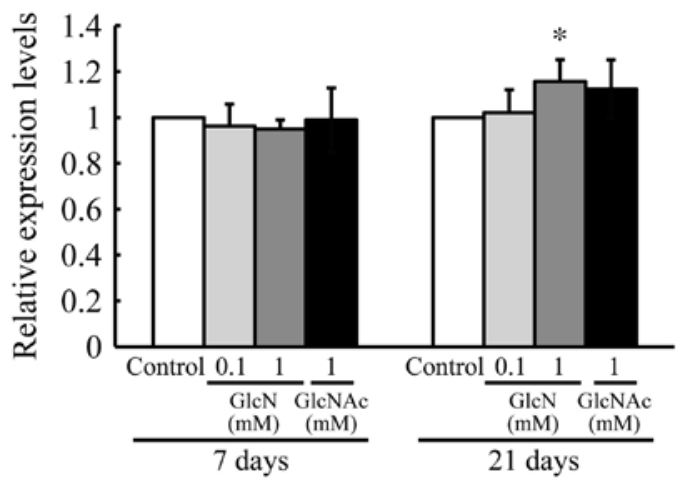

Figure 5. Effects of GlcN and GlcNAc on the mRNA expression of osteocalcin $(\mathrm{OCN})$. Osteoblastic cells (MC3T3-E1) were differentiated in differentiation medium in the absence (Control) or presence of $\mathrm{GlcN}(0.1$ and $1 \mathrm{mM})$ or GlcNAc $(1 \mathrm{mM})$ for 21 days. After the incubation, total-RNA was purified, and the OCN mRNA expression was evaluated by RT-PCR. (A) PCR products were resolved by $2 \%$ agarose gel electrophoresis, and stained with ethidium bromide. (B) OCN mRNA expression is expressed as a ratio relative to Control. Data represent the mean $\pm \mathrm{SD}$ of three independent experiments. Values were compared between the absence (Control) and presence of GlcN or GlcNAc. ${ }^{*} \mathrm{P}<0.05$.

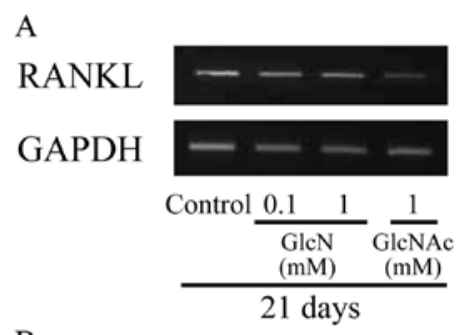

B

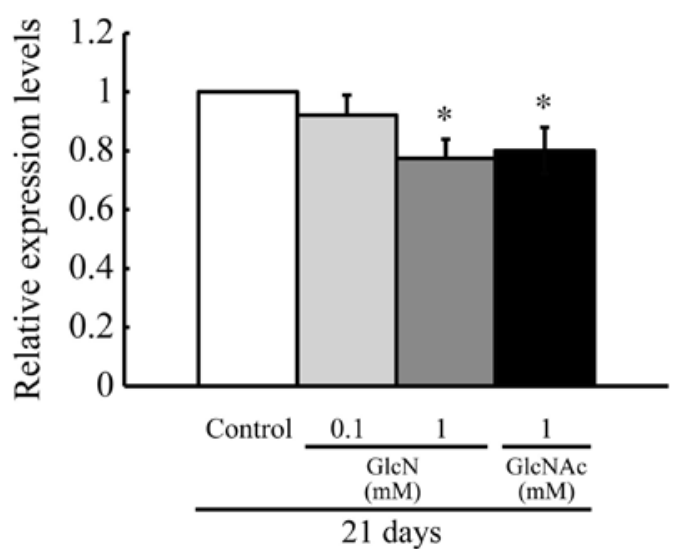

Figure 6. Effects of GlcN and GlcNAc on the mRNA expression of RANKL. Osteoblastic cells (MC3T3-E1) were differentiated in differentiation medium in the absence (Control) or presence of GlcN $(0.1$ and $1 \mathrm{mM})$ or GlcNAc $(1 \mathrm{mM})$ for 21 days. After the incubation, total RNA was purified, and the RANKL mRNA expression was evaluated by RT-PCR. (A) PCR products were resolved by $2 \%$ agarose gel electrophoresis, and stained with ethidium bromide. (B) RANKL mRNA expression is expressed as a ratio relative to Control. Data represent the mean \pm SD of three independent experiments. Values were compared between the absence (Control) and presence of GlcN or GlcNAc. ${ }^{*} \mathrm{P}<0.05$. 
by both GlcN and GlcNAc (1 $\mathrm{mM})$ after incubation for 21 days (Fig. 6).

\section{Discussion}

$\mathrm{OA}$ is characterized by qualitative and quantitative changes in the architecture and composition of all the joint structures $(1,2)$. GlcN has been used to treat OA in humans, because it is present in the cartilage tissues as a component of glycosaminoglycans (35), and exhibits symptom-modifying effects on OA by normalizing cartilage metabolism $(6-8,13-15)$.

On the other hand, the pathological change of subchondral bone is implicated in the initiation and progression of cartilage damage in OA (18). Due to non-physiological load-bearing to the subchondral bone, the bone resorption increases, thereby enhancing the progression of OA (19). However, the effect of $\mathrm{GlcN}$ on bone metabolism remains unsolved.

There are a few reports on the effects of GlcN on bone metabolism. First, a GlcN-containing diet has been shown to increase the bone mineral density of the femur in mice (36); however, the involved mechanism was not clarified. Second, GlcN treatment was reported to increase the ALP activity in NOS-1 cells, a human osteoblastic cell line (37). Third, $\mathrm{GlcN}$ treatment was found to increase OCN secretion from MG-63 cells, a human osteoblastic cell line, whereas collagen synthesis was not affected by GlcN (38). However, in these studies, only a few markers were used for evaluating the effect of GlcN on bone metabolism. Moreover, the effect of GlcNAc, a derivative of GlcN, has never been assessed.

In this study, we determined the effect of GlcN on bone metabolism (osteoblastic cell differentiation) using mouse MC3T3-E1 osteoblasts by evaluating the expression of differentiation markers of the early (COLI and ALP), middle (OPN) and late (OCN and mineralization) stages, and further compared the GlcN effects with those of GlcNAc. The results indicate that mineralization of mature osteoblasts is increased by treatment with GlcN after incubation for 21 days (Fig. 1). Furthermore, RT-PCR analyses revealed that GlcN treatment substantially increased the expression of a middle stage marker (OPN) and a late stage marker (OCN) after incubation for 21 days, whereas it did not essentially affect the expression of early stage markers (COLI and ALP) (Figs. 2-5). In addition, GlcN treatment suppressed the expression of RANKL, which regulates the differentiation and activation of osteoclasts, cells involved in the resorption of bone matrix (Fig. 6). Together these observations likely suggest that GlcN not only induces osteoblastic cell differentiation especially at the middle-late stages, but also suppresses osteoclastic cell differentiation, thereby increasing bone matrix deposition and decreasing bore resorption, eventually promoting bone formation (Fig. 7). This finding may explain the underlying mechanism for the observed increased mineral density of the bone in mice after the dietary supplementation with GlcN (36).

It is now recognized that the addition of $\mathrm{O}$-linked $\mathrm{N}$-acetylglucosamine (O-GlcNAc) mediated by O-GlcNAc transferase to a serine or threonine residue of target proteins modulates cellular functions, such as nuclear transport, transcription, translation, cell signaling, apoptosis and cell shape $(39,40)$. In this context, it has been revealed that several transcription factors are modified by O-GlcNAc, and such

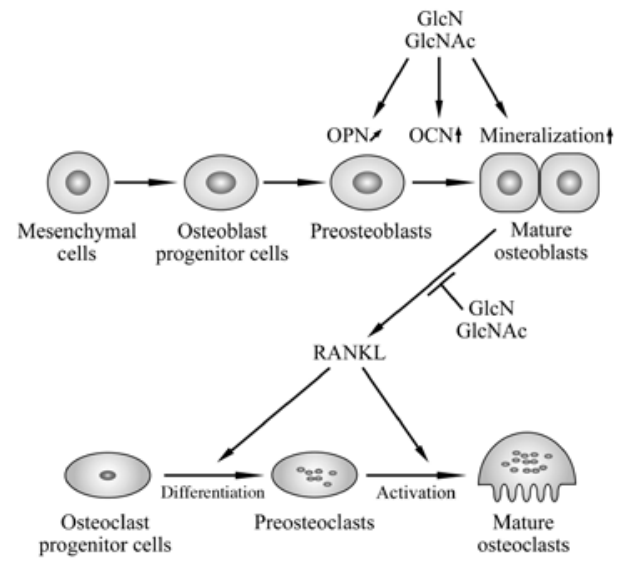

Figure 7. Schematic representation of the effects of GlcN and GlcNAc on the osteoblastic and osteoclastic cell differentiation. GlcN and GlcNAc increase the mineralization of mature osteoblasts and the expression of middle and late stage markers (OPN and OCN, respectively) during osteoblastic differentiation, and reduce the expression of RANKL, a differentiation and activation factor for osteoclasts, thereby possibly increasing bone matrix deposition and decreasing bone resorption to promote the bone formation.

modification regulates the transcriptional activities of the genes (41-45); for instance, the increased O-GlcNAc modification of the runt-related transcription factor 2 (RUNX2) regulates the transcription of OCN, a target gene of RUNX2 (46). Moreover, we previously demonstrated that O-GlcNAc modification was increased by $\mathrm{GlcN}$ in endothelial cells $(47,48)$. Thus, it is interesting to speculate that the O-GlcNAc modification is similarly induced by $\mathrm{GlcN}$ in osteoblasts, thereby modulating the transcriptional expression of the genes (differentiation markers) for the osteoblastic and osteoclastic cell differentiation, as observed in this study.

Furthermore, the present results demonstrate that GlcNAc, a derivative of GlcN, as well as $\mathrm{GlcN}$ is able to increase the mineralization of mature osteoblasts and the expression of a middle stage marker (OPN) and a late stage marker (OCN) for osteoblastic cell differentiation, and to suppress the expression of RANKL, a key factor involved in the osteoclastic cell differentiation and activation (Figs. 1-6). These observations likely suggest that not only GlcN, but also GlcNAc, has a potential to induce osteoblastic cell differentiation and to suppress osteoclastic cell differentiation, thereby promoting bone formation (Fig. 7). In support of this finding, it has been recently reported that oral administration of GlcNAc increases bone mineral density in $\mathrm{C} 57 \mathrm{BL} / 6 \mathrm{~J}$ mice, possibly by promoting bone formation and suppressing bone resorption (49).

In conclusion, the present study revealed that GlcN and GlcNAc increase the mineralization of mature osteoblasts and the expression of middle and late stage markers (OPN and $\mathrm{OCN}$, respectively) during osteoblastic differentiation, and reduce the expression of RANKL, a differentiation and activation factor of osteoclasts. Together these observations likely suggest that both GlcN and GlcNAc may have a potential to induce osteoblastic cell differentiation, and to suppress osteoclastic cell differentiation, thereby increasing bone matrix deposition and decreasing bone resorption to modulate bone metabolism in OA. However, the effect of GlcN and GlcNAc on bone metabolism in OA should be carefully evaluated in the future. 


\section{Acknowledgements}

This study was partially supported by the Research Institute for Diseases of Old Age, Juntendo University School of Medicine.

\section{References}

1. Gabriel SE, Crowson CS, Campion ME and O'Fallon WM Direct medical costs unique to people with arthritis. J Rheumatol 24: 719-725, 1997.

2. March LM and Bachmeier CJ: Economics of osteoarthritis: a global perspective. Baillieres Clin Rheumatol 11: 817-834, 1997.

3. Martel-Pelletier J, Lajeunesse D and Pelletier JP: Etiopathogenesis of osteoarthritis. In: Arthritis and Allied Conditions: A Textbook of Rheumatology. Vol 2. 15th edition. Koopman WJ and Moreland LW (eds). Lippincott Williams \& Wilkins, Philadelphia, pp2199-2226, 2005.

4. Puhl W, Bernau A, Greiling H, Köpcke W, Pförringer W, Steck KJ, Zacher J and Scharf HP: Intra-articular sodium hyaluronate in osteoarthritis of the knee: a multicenter, double-blind study. Osteoarthritis Cartilage 1: 233-241, 1993.

5. Buckwalter JA and Mankin HJ: Articular cartilage: degeneration and osteoarthritis, repair, regeneration, and transplantation. Instr Course Lect 47: 487-504, 1998.

6. Fenton JI, Chlebek-Brown KA, Peters TL, Caron JP and Orth MW: Glucosamine $\mathrm{HCl}$ reduces equine articular cartilage degradation in explant culture. Osteoarthritis Cartilage 8: 258-265, 2000.

7. Gouze JN, Bordji K, Gulberti S, Terlain B, Netter P, Magdalou J, Fournel-Gigleux $S$ and Ouzzine $M$ : Interleukin- $1 \beta$ downregulates the expression of glucuronosyltransferase I, a key enzyme priming glycosaminoglycan biosynthesis: influence of glucosamine on interleukin-1 $\beta$-mediated effects in rat chondrocytes. Arthritis Rheum 44: 351-360, 2001

8. Oegema TR Jr, Deloria LB, Sandy JD and Hart DA: Effect of oral glucosamine on cartilage and meniscus in normal and chymopapaininjected knees of young rabbits. Arthritis Rheum 46: 2495-2503, 2002.

9. Crolle $\mathrm{G}$ and D'Este E: Glucosamine sulphate for the management of arthrosis: a controlled clinical investigation. Curr Med Res Opin 7: 104-109, 1980.

10. Drovanti A, Bignamini AA and Rovati AL: Therapeutic activity of oral glucosamine sulfate in osteoarthrosis: a placebo-controlled double-blind investigation. Clin Ther 3: 260-272, 1980.

11. Tapadinhas MJ, Rivera IC and Bignamini AA: Oral glucosamine sulphate in the management of arthrosis: report on a multi-centre open investigation in Portugal. Pharmatherapeutica 3: 157-168, 1982.

12. Lopes VA: Double-blind clinical evaluation of the relative efficacy of ibuprofen and glucosamine sulphate in the management of ostearthrosis of the knee in out-patients. Curr Med Res Opin 8: 145-149, 1982.

13. McAlindon TE, LaValley MP, Gulin JP and Felson DT: Glucosamine and chondroitin for treatment of osteoarthritis: a systematic quality assessment and meta-analysis. JAMA 283: 1469-1475, 2000.

14. Reginster JY, Deroisy R, Rovati LC, Lee RL, Lejeune E, Bruyene O, Giacovelli G, Henrotin Y, Dacre JE and Gossett C: Long-term effects of glucosamine sulphate on osteoarthritis progression: a randomised, placebo-controlled clinical trial. Lancet 357: 251-256, 2001.

15. Pavelka K, Gatterova J, Olejarova M, Machacek S, Giacovelli G and Rovati LC: Glucosamine sulfate use and delay of progression of knee osteoarthritis: a 3-year, randomized, placebo-controlled, double-blind study. Arch Intern Med 162: 2113-2123, 2002.

16. Zhang W, Moskowitz RW, Nuki G, Abramson S, Altman RD, Arden N, Bierma-Zeinstra S, Brandt KD, Croft P, Doherty M, Dougados M, Hochberg M, Hunter DJ, Kwoh K, Lohmander LS and Tugwell P: OARSI recommendations for the management of hip and knee osteoarthritis, Part II: OARSI evidence-based, expert consensus guidelines. Osteoarthritis Cartilage 16: 137-162, 2008.

17. Hua J, Sakamoto K, Kikukawa T, Abe C, Kurosawa $\mathrm{H}$ and Nagaoka I: Evaluation of the suppressive actions of glucosamine on the interleukin-1 $\beta$-mediated activation of synoviocytes. Inflamm Res 56: 432-438, 2007.

18. Radin EL and Rose RM: Role of subchondral bone in the initiation and progression of cartilage damage. Clin Orthop Relat Res 213: 34-40, 1986.
19. Bettica P, Cline G, Hart DJ, Meyer J and Spector TD: Evidence for increased bone resorption on patients with progressive knee osteoarthritis. Arthritis Rheum 46: 3178-3184, 2002

20. Saito Y, Yoshizawa T, Takizawa F, Ikegame M, Ishibashi O, Okuda K, Hara K, Ishibashi K, Obinata M and Kawashima H: A cell line with characteristics of the periodontal ligament fibroblasts is negatively regulated for mineralization and Runx $2 /$ Cbfa1/Osf2 activity, part of which can be overcome by bone morphogenetic protein-2. J Cell Sci 115: 4191-4200, 2002

21. Yoshizawa T, Takizawa F, Iizawa F, Ishibashi O, Kawashima H, Matsuda A, Endo N and Kawashima H: Homeobox protein Msx2 acts as a molecular defense mechanism for preventing ossification in ligament fibroblasts. Mol Cell Biol 24: 3460-3472, 2004.

22. Stanford CM, Jacobson PA, Eanes ED, Lembke LA and Midura RJ: Rapidly forming apatitic mineral in an osteoblastic cell line (UMR 106-01 BSP). J Biol Chem 270: 9420-9428, 1995.

23. Ali MM, Yoshizawa T, Ishibashi O, Matsuda A, Ikegame $M$, Shimomura J, Mera H, Nakashima $K$ and Kawashima $H$ : PIASx $\beta$ is a key regulator of osterix transcriptional activity and matrix mineralization in osteoblasts. J Cell Sci 120: 2565-2573, 2007.

24. Bronckers AL, Gay S, Finkelman RD and Butler WT: Developmental appearance of the Gla proteins (osteocalcin) and alkaline phosphatase in tooth germs and bone of the rat. Bone Miner 2: 361-373, 1987.

25. Rodan GA, Heath JK, Yoon K, Noda M and Rodan SB: Diversity of the osteoblastic phenotype. In: Cell and Molecular Biology of Vertebrate Hard Tissues, Ciba Foundation Symposium 136. Everd D and Harnett S (eds). John Wiley and Sons, Ltd., Chichester, UK, pp78-91, 1988.

26. Weinreb M, Shinar D and Rodan GA: Different pattern of alkaline phosphatase, osteopontin, and osteocalcin expression in developing rat bone visualized by in situ hybridization. J Bone Miner Res 5: 831-842, 1990.

27. Ibaraki K, Termine JD, Whitson SW and Young MF: Bone matrix mRNA expression in differentiating fetal bovine osteoblasts. J Bone Miner Res 7: 743-754, 1992.

28. Stein GS and Lian JB: Molecular mechanisms mediating proliferation/differentiation interrelationships during progressive development of the osteoblast phenotype. Endocr Rev 14: 424-442, 1993.

29. Malaval L, Modrowski D, Gupta AK and Aubin JE: Cellular expression of bone-related proteins during in vitro osteogenesis in rat bone marrow stromal cell cultures. J Cell Physiol 158: 555-572, 1994.

30. Eriebacher A, Filvaroff EH, Gitelman SE and Derynck R: Toward a molecular understanding of skeletal development. Cell 80: 371-378, 1995.

31. Reddi AH: Bone morphogenesis and modeling: soluble signal sculpt osteosomes in the solid state. Cell 89: 159-161, 1997.

32. Filvaroff $\mathrm{E}$ and Derynck R: Bone remodeling: a signaling system for osteoclast regulation. Curr Biol 8: R679-R682, 1998.

33. Lacey DL, Timms E, Tan H-L, Kelley MJ, Dunstan CR, Burgess T, Elliot R, Colombero A, Elliott G, Scully S, Hsu H, Sullivan J, Hawkins N, Davy E, Capparelli C, Eli A, Qian Y-X, Kaufman S, Sarosi I, Shalhoub V, Senaldi G, Guo J, Delaney J and Boyle WJ: Osteoprotegerin ligand is a cytokine that regulates osteoclast differentiation and activation. Cell 93: $165-176,1998$.

34. Kobayashi Y, Udagawa $\mathrm{N}$ and Takahashi N: Action of RANKL and OPG for osteoclastogenesis. Crit Rev Eukaryot Gene Expr 19: 61-72, 2009.

35. Divine JG, Zazulak BT and Hewett TE: Viscosupplementation for knee osteoarthritis. Clin Orthop Relat Res 455: 113-122, 2006.

36. Yamazaki H, Mano H, Nakatani S and Wada M: The intake of glucosamine increased bone mass by pQCT in ddy mice. Glucosamine Res 3: 1-6, 2007.

37. Matsunaga T, Yanagiguchi K, Yamada S, Ohara N and Ikeda T: Chitosan monomer promotes tissue regeneration on dental pulp wounds. J Biomed Mater Res 76: 711-720, 2006.

38. Kim MM, Mendis E, Rajaoakse N and Kim SK: Glucosamine sulfate promotes osteoblastic differentiation of MG-63 cells via anti-inflammatory effect. Bioorg Med Chem Lett 17: 1938-1942, 2007.

39. Wells L, Whelan SA and Hart WG: O-GlcNAc: a regulatory post-translational modification. Biochem Biophys Res Commun 302: 435-441, 2003.

40. Love DC and Hanover JA: The hexosamine signaling pathway: deciphering the O-GlcNAc code (Review). Sci STKE 312: re13, 2005. 
41. Chou TY, Dang CV and Hart GW: Glycosylation of the c-myc transactivation domain. Proc Natl Acad Sci USA 92: 4417-4421, 1995.

42. Han I and Kudlow JE: Reduced O glycosylation of Sp1 is associated with increased proteasome susceptibility. Mol Cell Biol 17: 2550-2558, 1997.

43. Jiang MS and Hart GW: A subpopulation of estrogen receptors are modified by $\mathrm{O}$-linked $\mathrm{N}$-acetylglucosamine. J Biol Chem 272: 2421-2428, 1997.

44. Yang WH, Kim JE, Nam HW, Ju JW, Kim HS Kim YS and Cho JW: Modification of p53 with O-linked N-acetylglucosamine regulates p53 activity and stability. Nat Cell Biol 8: 1074-1083, 2006.

45. Fujiki R, Chikanishi T, Hashiba W, Ito H, Takada I, Roeder RG, Kitagawa $\mathrm{H}$ and Kato S: GlcNAcylation of a histone methyltransferase in retinoic-acid-induced granulopoiesis. Nature 459: 455-461, 2009.
46. Kim S-H, Kim Y-H, Song M, An SH, Byun H-Y, Heo K, Lim S, Oh Y-S, Ryu SH and Suh P-G: O-GlcNAc modification modulates the expression of osteocalcin via OSE2 and Runx2. Biochem Biophys Res Commun 362: 325-329, 2007.

47. Ju Y, Hua J, Sakamoto K, Ogawa H and Nagaoka I: Glucosamine, a naturally occurring amino monosaccharide modulates LL-37induced endothelial cell activation. Int J Mol Med 22: 657-662, 2008.

48. Ju Y, Hua J, Sakamoto K, Ogawa H and Nagaoka I: Modulation of TNF- $\alpha$-induced endothelial cell activation by glucosamine, a naturally occurring amino monosaccharide. Int J Mol Med 22: 809-815, 2008.

49. Shimizu T, Nakatani S, Kobata K and Wada M: Oral administration of N-acetyl-D-glucosamine and D-glucosamine hydrochloride affects bone mineral density in C57BL/6J mice. Chitin Chitosan Res 17: 74-78, 2011. 